\title{
Desafios à pesquisa no Serviço Social: da formação acadêmica à prática profissional
}

\author{
Aglair Alencar Setubal \\ Curso de Serviço Social do Instituto Camillo Filho (ICF-Piauí)
}

\section{Desafios à pesquisa no Serviço Social: da formação acadêmica à prática profissional}

Resumo: As reflexões contidas neste ensaio objetivam chamar a atenção dos profissionais, professores e alunos de Serviço Social para a importância da pesquisa nos diferentes contextos de atuação nesta área, apesar dos desafios e dificuldades apresentados a sua realização. Apresentam-se possibilidades de operacionalização da pesquisa para uma intervenção profissional crítica, condizente com a realidade concreta - contexto da prática profissional; a sua importância para um fazer-se histórico do Serviço Social centrado em posturas teórico-metodológicas que dêem conta da riqueza, complexidade e essência da realidade, rompendo com a pseudoconcreticidade, com a práxis utilitária, manipuladora e construída na dimensão da 'consciência comum'. Apesar da importância atribuída à pesquisa, procura-se evitar que esta seja vista deslocada da realidade humano-social, já que é neste contexto que ela adquire significado, atinge a sua acepção e dá conta das necessidades do Serviço Social como profissão histórica.

Palavras-chave: formação acadêmica, pesquisa, prática profissional, práxis social, transformação social.

\section{Challenges to Social Work Research: From Academic Education to Professional Practice}

Abstract: The reflections contained in this essay seek to the call attention of professionals, professors and students of Social Work to the importance of research in the various contexts of activity in this field, despite the challenges and difficulties presented in its realization. It offers possibilities for conducting research from a critical professional intervention, in keeping with the concrete reality - the context of professional practice. It also highlights the importance for the preparation of a history of Social Work based on theoretical-methodological postures that consider the wealth, complexity and essence of reality, breaking with the 'pseudoconcreticity', with the utilitarian, manipulative praxis that is constructed in the dimension of a 'common consciousness'. Despite the importance attributed to research, it sought to avoid separating it from human-social reality, given that it is in this context that research acquires meaning, becomes accepted and considers the needs of Social Work as a historic profession.

Key words: academic education, research, professional practice, social praxis, social transformation. 
A investigação que visa diretamente à essência, ao deixar para trás tudo aquilo que é inessencial, como lastro supérfluo, lança dúvida quanto a sua própria legitimidade.

Karel Kosik

Para se penetrar no mundo das coisas, para se entender, analisar e interpretar a realidade na sua riqueza complexa e na sua totalidade concreta tem que se desenvolver um esforço intelectivo capaz de apreender a essência delas na sua mediaticidade.

Diferente do fenômeno que se pode observar na imediaticidade, a essência de uma realidade só se revela após o ato investigativo que procura no mesmo processo identificar a estrutura da realidade concreta, não na sua manifestação fenomênica, mas pela identificação das múltiplas determinações que lhes são peculiares e que lhes dão sentido e força para existir em determinado tempo e sociedade.

Todavia, apesar de se reconhecer essa conduta como imprescindível por parte do sujeito cognoscente, considera-se redutora da realidade a atitude investigativa que, como diz Kosik (1976, p.57) no trecho utilizado como epígrafe deste trabalho, deixa "[...] para trás tudo aquilo que é inessencial, como lastro supérfluo [...]". Explica-se, numa ordem inversa a esse pensamento, mas sem uma configuração linear - como a realidade não apresenta a sua concreticidade de forma direta, ou seja, não se revela tal como ela é -, o homem no seu estado natural só é capaz de se aproximar da realidade superficialmente; apenas a percebe naquilo que ela manifesta e que é possível captar pelos sentidos. Essa captação, por sua vez, é resultante das forças circundantes da sua existência, e não revela, como se pode imaginar a priori, uma conduta passiva desse sujeito, mas sim a concepção que esse homem historicamente construiu sobre a realidade. Para que o homem ultrapasse o estágio do sensível e caminhe em direção à 'coisa em si', a essência da realidade, ele tem que sair da conduta contemplativa/reflexiva ${ }^{1}$ para se por em ação pela práxis transformadora. Transformadora por não considerar o fenômeno como algo independente e absoluto, já que esse se transforma em relação com a essência e só é compreendido quando se atinge a estrutura da 'coisa em si'.

Apesar de o Serviço Social, a partir, principalmente, das duas últimas décadas do século 20, ter se aproximado da vertente marxista e, em decorrência dessa 'filiação', empreendido esforços no sentido de desenvolver pesquisas utilizando o método dialéticohistórico, percebe-se certa dificuldade por parte de alguns profissionais de vivenciarem a práxis como resultante da atividade do homem no seu fazer-se histórico. Em decorrência disso, existem no Serviço Social estudos que, aparentemente orientados pela vertente teórica marxista, tangenciam a prática pro- fissional de alguns assistentes sociais que, na contra mão da história, insistem em desenvolver atos ${ }^{2}$ desarticulados e justapostos, em espaços institucionais alheios até mesmo às orientações do positivismo.

A coexistência de correntes teóricas de interesses e métodos tão diferentes tem dificultado o rompimento com a conduta norteada pela pseudoconcreticidade $^{3}$ e o desvencilhamento da compreensão que se tem da práxis como sinônimo de trabalho ${ }^{4}$.

Aparentemente, as dificuldades são de fácil solução, mesmo se reconhecendo a força de fatores externos que mumificam conceitos, impedem que o assistente social - esteja ele no desempenho da prática acadêmica, investigativa ou de intervenção direta na realidade - desvende, por intermédio da análise dos conceitos, os significados e significâncias neles presentes, a riqueza e complexidade da coisa por ele representada; penetre enquanto agente social e profissional no pensamento do homem em ação/atividade e não no ato.

Acredita-se ser essa uma das condições indispensáveis ao Serviço Social, o qual se propõe crítico e não permite a sacralização da 'prática profissional', que intervém de forma imediatista dando respostas aos problemas de identificação apenas sensível. São problemas que, muitas vezes, justificam a criação de políticas sociais reafirmadoras das facetas pelas quais a questão social se explicita, em determinado contexto e tempo, funcionando como elementos basilares do discurso instituído. Discurso propagado como verdade absoluta por alguns assistentes sociais, que são impedidos por motivos adversos à sua vontade de transformar a prática profissional em práxis social, o que, segundo Vázquez (1968, p. 200), constitui uma atividade política.

Como a práxis social é uma atividade política que, conforme o mesmo autor, pode mudar as relações econômicas, sociais e políticas, ela exige o desenvolvimento de ações integradas dos diferentes setores da sociedade e não ações pontuais já que a solução dos problemas sociais não se contituí responsabilidade de uma área de saber, de determinada categoria profissional.

Percebe-se que esta postura tem dificultado a prática da pesquisa, principalmente dentro da dimensão da dialética histórica, pelo Serviço Social. Entretanto, apesar das dificuldades apresentadas contribuírem para um pensar-agir dicotômico, acredita-se que a produção do conhecimento pela via da pesquisa é o caminho que possibilita o rompimento do Serviço Social com a pseudoconcreticidade, por provocar no profissional o desejo de se movimentar - enquanto pesquisador e/ou profissional responsável por ações institucionais que, aparentemente, não têm responsabilidade direta de produzir conhecimento - no sentido de fazer com que o pensar e o agir possam interagir dialeticamente. Com esse processo espera- 
se provocar a eliminação da concepção fetichizada que se satisfaz com a aparência da coisa, desenvolvendo uma práxis utilitária, manipuladora, construída na dimensão da "consciência comum", "consciência ingênua" ou "falsa consciência" como diz Kosik ${ }^{5}$.

Além disso, é fundamental considerar a práxis ${ }^{6}$ como esfera do ser humano que evidencia a criação, a existência e a experiência como humano-sociais.

A criação, nesse contexto, é uma realidade ontológica ${ }^{7}$ decorrente do processo 'ontocriativo' unificador das compreensões de mundo e da realidade humana sem primado entre essas concepções. Conseqüientemente, não atribui importância maior à teoria ou à prática, ao visível (fenômeno) e à essência, evitando-se com isso a construção de percepções unilateralizantes, ou duais que preconizam o poder do saber desconsiderando o verdadeiro significado da teoria. Teoria que só atinge a sua significância quando expressa a realidade humano-social, o momento existencial dos autores e atores, razão do seu existir ${ }^{8}$.

Quando as reflexões são transportadas para o interior do Serviço Social não se deve apenas explicitar dificuldade em assimilar e colocar em prática as exigências da dialética histórica, em vivenciar, como um todo, no seu cotidiano profissional a concretização da práxis social, mas iniciar a reflexão pela dimensão política presente no contexto das relações sociais e pela forma de inserção dessa profissão no mercado de trabalho.

Por isso, a influência da forma de inserção pela via da divisão social do trabalho não pode ser ignorada quando se estuda e se analisa a construção das peculiaridades que levaram o Serviço Social, ao longo dos tempos, a trabalhar com uma identidade atribuída, em que o saber está a serviço do capitalismo.

Para as pessoas mais apressadas na leitura da 'realidade', essas reflexões nada têm a ver com a temática deste trabalho, não passando de mera elucubração teórica. Respeita-se a leitura, embora se discorde do entendimento, uma vez que só pela identificação, compreensão e pelo conhecimento das condições históricas do Serviço Social pode-se identificar os desafios em relação à pesquisa e à consolidação da área como produtora e disseminadora de conhecimento, apesar de ser detentora de profissionais capacitados para a prática investigativa.

O número crescente de publicações é revelador da preocupação, do interesse e/ou da necessidade do Serviço Social em desenvolver pesquisa, daí ser possível, hoje, no Brasil encontrar vasta produção de conhecimentos na área.

Entretanto, quando se procura identificar os autores, logo se percebe que o esforço investigativo resulta, na sua grande maioria, de elaborações de assistentes sociais ligados à docência stricto sensu (mestrado e principalmente doutorado), ou de professores que procuram, por exigência das Instituições de Ensino Superior (IES), a titulação de mes- tres e doutores em Serviço Social, Ciências Sociais, Educação, Ciências Políticas, entre outros Programas de Pós-Graduação. Com raras exceções se identificam trabalhos não vinculados ao mundo acadêmico ou por exigência desse universo em seus diferentes níveis para obtenção de títulos.

Essa constatação conduz a algumas indagações, que envolvem não apenas os profissionais que realizam atividades desvinculadas do ensino, mas também os assistentes sociais responsáveis pela formação acadêmica dos que procuram o Serviço Social como profissão. Daí se perguntar: como se explica a produção do conhecimento, embora tendo como objeto de pesquisa aspectos das expressões das questões sociais que justificam a existência do Serviço Social, não ser constante no fazer-se histórico da profissão? O que justifica a prática profissional descomprometida com o conhecimento da essência dos problemas sociais, da estrutura da questão social? Quais são as forças presentes no Serviço Social, para que a sazonalidade da pesquisa detectada por Setubal (1995) ainda seja tão presente no Serviço Social, apesar da crescente produção científica hoje existente e da identificação por esta autora dos "elementos influenciadores e limites que se colocam na prática da pesquisa"?

São muitas as questões possíveis de serem levantadas pelas mentes inquietas existentes no Serviço Social. Por isso é que se vê como necessário o desenvolvimento da prática investigativa, não apenas para cumprir exigências institucionais de ordem acadêmica, mas também para cumprir exigências do Serviço Social como profisssão historicamente situada.

A pesquisa no Serviço Social deve ir além das necessidades citadas neste trabalho, pois se defende a compreensão que, conscientemente, atribui importância e que, conseqüentemente, gera necessidades fomentadas pelo compromisso político-profissional do assistente social de realizar essa atividade; das necessidades sentidas pelos autores e atores profissionais envolvidos de vivenciarem a práxis social em detrimento da práxis repetitiva, em que os gestos e os atos são efetivados em círculos determinados, e da "práxis mimétrica" que, de acordo com Lefebvre (1979, p. 39), está em um nível que apenas segue modelos que, sem saber o porquê e o para quê da ação, não atingem a criação.

Somente a práxis transformadora viabiliza a criação que "[...] compreende a decisão teórica como a decisão de ação. Supõe tática e estratégia. Não existe atividade sem projeto; ato sem programa, práxis política sem exploração do possível e do futuro" (LEFEBVRE, 1979, p. 41).

Apesar dos avanços do Serviço Social, principalmente iniciado com o movimento de reconceituação, que acicataram os assistentes sociais a buscar novas alternativas de prática, dessa feita articulada com as 
práticas concretas das classes sociais, constata-se ainda, na primeira década do século 21 , vivências profissionais anacrônicas que nada lembram as con quistas históricas da profissão, sobretudo no plano teórico-metodológico. São atos que jamais serão atividades. A submersão em condutas letárgicas impede de desvelar a riqueza complexa da realidade concreta, por isso são prejudiciais ao movimento de transformação.

Diante desse quadro contraditório, vivenciado pelo Serviço Social, recorremos a Martinelli (1990, p. 17) quando diz "pensar o Serviço Social: eis a tarefa". Tarefa que parece inviável sem a adoção da consciência crítica pautada na história e estruturada em consonância com a situação do homem, no processo de construção da sua vida e da vida dos outros homens e até da natureza.

Marx e Engels (1977, p. 42) afirmam que a produção da vida tem "[...] dupla relação: de um lado, como relação natural, de outro como relação social social no sentido de que se entende por isso a cooperação de vários indivíduos, quaisquer que sejam as condições, o modo e a finalidade".

Vê-se com isso que a consciência do homem, longe de ser pura, é social, uma vez que é construída no "[...] interior do desenvolvimento histórico real". Assim sendo, não é a consciência que forma o homem, mas é o homem que forma a consciência de acordo com a sua situação, nas relações sociais e de trabalho (MARX; ENGELS, 1977, p. 44).

Neste momento, ressurgem novas reflexões suscitadas pela proposição anteriormente apresentada "pensar o Serviço Social: eis a tarefa". Tarefa que requer a capacidade de reconhecer as diferenças e ao mesmo tempo as relações intrínsecas entre a essência e o fenômeno tanto do ser, quanto do vir a ser do Serviço Social. Elementos que têm como exigência o respeito à sua processualidade, por ocasião dos estudos e trabalhos que, dialeticamente, têm que ser vivenciados pelo assistente social no desenvolvimento de sua prática e construção da identidade profissional.

"Pensar o Serviço Social [...]" sem se deter na reflexão pela reflexão, mas pensar/agir (atividade), transformar a realidade a partir da movimentação íntima entre esses processos que, apesar de diversos, compõem a unidade, apresentam saídas para questões ambíguas, decorrentes de teorias que não dão conta da leitura crítica da realidade e nem subsi- diam as respostas demandadas à profissão, face à pluralidade de problemas decorrentes das formas de manifestação da questão social. Manifestações e/ou expressões que constituem os verdadeiros objetos de trabalho do Serviço Social ${ }^{9}$.

"Pensar o Serviço Social [...]", do ponto de vista da pesquisa, requer que exista na profissão a clareza da amplitude do projeto éticopolítico construído, desde a legalização da profissão no Brasil, e reconstruído a partir das bases apontadas. $\mathrm{O}$ conhecimento constituído possibilitará criar e/ou descobrir as conexões necessárias entre esse projeto e o mercado de trabalho.

Entrar no campo desse conhecimento requer que as IES, por intermédio dos cursos de Serviço Social, tenham claramente definidos os seus projetos pedagógicos, tomando por base suas Diretrizes Curriculares. Conteúdos que viabilizem não só a inserção dos egressos do curso ao mercado de trabalho, mas também uma fundamentação teórico-metodológica, que assegure um agir-refletir crítico e uma intervenção que possa contribuir para a transformação social, cuja responsabilidade é de toda a sociedade e não somente do Serviço Social.

Consideram-se inconteste as necessidades do Serviço Social (na busca de aproximação do seu objeto histórico) de procurar entender, explicar, conhecer e apreender a realidade naquilo que lhe é essencial, com o apoio de procedimentos metodológicos cuidadosamente planejados e de uma sólida fundamentação teórica; realizar análise de situações concretas iniciando com a pesquisa da prática profissional na sua contextualidade e temporalidade histórica, ou seja, apreender a prática profissional no interior das múltiplas determinações do capitalismo contemporâneo.

Ao se atribuir importância à ação investigativa, longe de se negar a importância da dimensão interventiva, pretende-se mostrar a íntima relação existente entre teoria e prática e a condição de centralidade que esses processos devem ocupar na formação e na vida profissional. Devido a essa relação, o Serviço Social inscreveu a pesquisa como matéria já no primeiro currículo mínimo determinado pela Lei n. 1.889, de 13 de junho de 1953 que "dispõe sobre os objetivos do ensino do Serviço Social, sua estruturação e ainda as prerrogativas dos portadores de diplomas de Assistentes Sociais e Agentes Sociais" (BRASIL, 1996). E reafirmou a sua importância 
no segundo currículo mínimo por intermédio do Parecer n. 286, que foi aprovado em 19 de outubro de 1962 (BRASIL, 1962). Apenas no terceiro currículo recomendado no Parecer n. 242, aprovado em 13 de março de 1970 (BRASIL, 1970), a pesquisa não consta no elenco das matérias obrigatórias, por estar implícita no espírito integrador ensino-pesquisa da Reforma Universitária.

Com início em 1977, as unidades de ensino e a maestria da Associação Brasileira de Ensino de Serviço Social (ABESS, hoje ABEPSS) iniciam discussões sobre a reformulação do terceiro currículo mínimo, voltando a identificar a pesquisa como instrumento fundamental para uma sólida formação científica dos docentes e dos assistentes sociais na sua prática profissional. Dessas reflexões sobre a formação profissional resultou o quarto currículo, que foi aprovado por meio do Parecer n. 412/82, do Conselho Federal de Educação (BRASIL, 1982).

Já em 1996, as Diretrizes Curriculares, que viriam a ser estabelecidas pela Resolução n. 15, de março de 2002 (BRASIL, 2002) reiteravam a matéria pesquisa como parte dos princípios básicos da formação profissional.

Ao trazer para o centro a preocupação com a pesquisa, o Serviço Social reconhece a sua complexidade como profissão histórica, inserida e construída no movimento real da formação social capitalista. Procura não se contentar com a aparência da coisa, descobre caminhos que conduzem à apreensão da essência da realidade e, com isso, justifica a razão do existir da teoria e da ciência. Como diz Marx (1980, p. 939), "[...] toda ciência seria supérflua se houvesse coincidência imediata entre a aparência e a essência das coisas". Essência que só pode ser conhecida dentro da movimentação histórica.

A importância da história, no contexto desta reflexão, longe de ser uma preocupação somente com o passado do objeto de intervenção e do próprio Serviço Social, tem no seu cerne as questões unificadoras do ser e do vir a ser do Serviço Social, apreensão possível, apenas, dentro da dimensão da práxis transformadora, resultante das objetivações humanas, explicitadas paulatinamente ao longo da história.

Segundo Markus (1974), as objetivações são compreendidas tanto pelas forças produtivas materiais presentes na sociedade, quanto pela arte e pela filosofia. Aparentemente, esses três aspectos são insuficientes para dar conta da complexidade presente no cotidiano do indivíduo, enquanto ser particular. Contudo, constituem o tripé que sustenta as condições da vida humana; dão o design das experiências vivenciadas pelo homem, ser vivente e constituinte da sociedade, onde as leis do capital regem, de acordo com a sua lógica interna, o destino dos seus membros.

Pelo exposto neste trabalho, observa-se que, do ponto de vista da perspectiva teórica aqui adotada, o homem é concebido como sujeito histórico. Pertencendo a esta categoria, o assistente social é responsável, na condição de sujeito, pelo desempenho dos papéis de ator e autor da história; tem responsabilidades pelo ser e pelo vir a ser do Serviço Social. Esses, como a consciência, não são princípios formadores do assistente social, uma vez que, como profissional dentro das relações sociais e de trabalho, é ele que direciona, influencia, contribuí e dá concretude aos elementos na profissão.

Dessa forma, não se pode considerar as relações entre capital e trabalho como fator único, determinante, das condições objetivas para a construção do conhecimento nesta área. Não resta dúvida que elas são importantes, mas outros fatores permeiam as definições que põem o profissional em movimento e dão qualidade ao exercício profissional. Por esta razão, torna-se inaceitável, nos dias atuais, principalmente partindo de profissionais, há pouco tempo graduados e até pós-graduados (lato sensu), a defesa do discurso que prega ser o Serviço Social uma profissão eminentemente prática. Esse caráter constituiu a sua gênese no Brasil, por volta de 1936; foi fortemente cravado para compor o perfil do tipo de profissional que o sistema político brasileiro necessitava para dar 'resposta' à questão social, ou, melhor dizendo, às suas múltiplas expressões decorrentes: das desigualdades sociais, das injustiças sociais e da expropriação do homem, dos seus bens de produção.

É verdade que essa compreensão ainda se faz útil para as regras do sistema capitalista, que precisa de respostas imediatas e de profissionais para implementar, de forma acrítica, os programas sociais de caráter paliativos, focalistas, descomprometidos com a solução dos problemas e com o bem-estar social de abrangência universal. Com o passar dos anos, mudanças ocorreram, conjunturas e estruturas político-sociais assumiram novas configurações e adotaram novos mecanismos de exploração do homem. Instrumentos mais eficazes de extração da mais-valia foram criados e novas regras de mercado adotadas, para atender exigências internacionais de implementação de uma economia globalizada.

O Serviço Social como profissão historicamente construída se encontra entrelaçado por todas essas tramas, que marcam os sinais do tempo na realidade - em que o Serviço Social se efetiva -, que favorecem contradições internas no próprio sistema que as fecundam, que, paradoxalmente, favorecem o surgimento de fatos e de comportamentos suscitadores de ações que vão de encontro aos próprios interesses da estrutura que os produz.

O germe da contradição há muito posto já tem a sua visibilidade no seio da categoria. A definição de redimensionar a formação e, consequientemente, a prática do Serviço Social já está clara, após os debates fecundos ocorridos no interior da profissão. A idéia 
do Serviço Social concebido como profissão eminentemente ${ }^{10}$ prática vem sendo aos poucos eliminada pelo reconhecimento da obrigatoriedade dos profissionais de campo saberem apreender a realidade para nela introduzir mudanças.

O Serviço Social na contemporaneidade tem um cenário onde os seus profissionais, no empenho de fortalecer o estatuto de produtores de conhecimento para a profissão, lançam mão de diferentes formas de análise da realidade ${ }^{11}$. Formas que não apenas orientam a interpretação do objeto problematizado, mas, sobretudo, expressam as tendências ideológicas presentes nas lutas políticas existentes no interior da categoria, como reflexo de uma luta mais ampla de toda a sociedade.

As produções teóricas do Serviço Social são reveladoras dessas influências. Demonstram o quadro social, político e econômico em que o Serviço Social está configurado no momento da sua elaboração. Revelam a inexistência de um perfil universal para a profissão, preconizam a aproximação do assistente social da prática da pesquisa, independentemente da posição em que ele se encontra na divisão social e técnica do trabalho, seja apropriando-se da experiência enriquecedora, sistematização crítica da sua prática, do restabelecimento da relação teoriaprática, a partir do agir sintetizador e unificador, mas jamais simplificador.

Já se indagou neste trabalho sobre a sazonalidade e apontou-se alguns desafios enfrentados pelo Serviço Social em relação à pesquisa. Entretanto, não se pode ignorar o aumento desse tipo de produção na área, após a saída dos primeiros mestres e doutores dos Programas de Pós-Graduação em Serviço Social. Hoje, tem-se acesso aos trabalhos resultantes de pesquisas, tanto em forma de livros, quanto de artigos científicos publicados em periódicos de reconhecimento nacional, regional e até internacional, como a Revista Serviço Social e Sociedade e a Revista Katálysis, entre outras. Isso sem se falar nas produções científicas que apenas são socializadas em eventos.

Em relação a eventos e ao aumento da produção na área, vale lembrar o número de inscrições para o $X$ Encontro Nacional de Pesquisadores em Serviço Social (ENPESS), ocorrido entre 4 e 8 de dezembro de 2006, na Universidade Federal de Pernambuco ${ }^{12}$ : 850 pessoas entre discentes da graduação e pós-graduação, docentes, pesquisadores e profissionais de campo. Foram inscritos 1.328 trabalhos, sendo sele- cionados $754^{13}$, que foram distribuídos nas seguintes modalidades: 32 mesas coordenadas; 116 pôsteres e 465 comunicações orais. Além dessas modalidades de apresentação foram ainda selecionados 21 grupos de rede de pesquisa; 62 oficinas de teses e dissertações e 64 oficinas de iniciação científica ${ }^{14}$.

Esses números são significativos para uma profissão que ainda se apresenta jovem no mundo, que está cada vez mais a exigir a produção científica do saber. Além disso, são reveladores dos esforços, principalmente, de docentes e de discentes da pós-graduação em firmarem a pesquisa no contexto do Serviço Social. Revelam a coragem e o despertar para a importância da pesquisa logo no período inicial da formação profissional - a graduação -, apesar de as conjunturas universitárias, muitas vezes, se apresentarem adversas à produção do conhecimento, pelo privilégio do ensino na sua forma mais elementar, sala de aula, em detrimento da pesquisa e da extensão.

Ao desenvolverem políticas administrativas que dificultam e até inviabilizam o desenvolvimento da pesquisa, as IES descumprem o compromisso social e político de, por se firmarem numa realidade concreta, formar profissionais com capacidade para um intervir consequiente dentro de um projeto mais amplo de transformação da sociedade. Certamente, qualquer IES que se constrói com esse perfil claudica, por apenas sobreviver no marasmo da mediocridade intelectual.

É sabido que a universidade deve se sustentar no tripé: ensino, pesquisa e extensão. Entretanto, não são raras as instituições em que esse propósito se constitui em mera falácia, já que as três atividades são escassamente vivenciadas de forma integrada. Quando existem, ocorrem isoladamente, sem a preocupação da articulação necessária entre ensino, pesquisa e extensão, sem se falar no privilégio de um sobre o outro.

Acredita-se que os esforços coletivos, desenvolvidos por professores e alunos no sentido de implementar a pesquisa na universidade são fundamentais para o ensino, para a extensão e para a vida profissional. Só assim a formação acadêmica sairá do plano do ideal, do abstrato para dar corporeidade à prática profissional, seja ela desenvolvida na universidade, seja em outras instituições onde o assistente social funcionalmente se insera. É na relação pesquisa e ação, profissional e pesquisa que se adquire maturidade intelectual, que se desmistifica o aparente como realidade concreta, que 
se reconhece na realidade a sua complexidade e riqueza ao se constituir como totalidade.

A pesquisa é um dos procedimentos teóricometodológicos que, ao ser incorporado à prática profissional, poderá levar o assistente social a reinventar, reconstruir e até construir um vir a ser para o Serviço Social, a partir da eliminação da consciência acomodada e até adormecida. Permite uma auto-análise e revisão permanente dos que a praticam, uma compreensão do outro, com mais tolerância; o repensar o dito, o obrigado a ouvir e a aceitar, por ser procedente da autoridade produtora do conhecimento já reconhecido no meio da intelectualidade, ou da autoridade decorrente da função institucional. Ainda com a sustentação no estudo e na pesquisa, percebe-se que cada discurso é apenas uma forma de compreensão da realidade e não uma verdade absoluta sobre ela. Inumeráveis são as vantagens da pesquisa, para os que a praticam. Mas essa importância tem que ser exaltada desde os momentos iniciais da graduação por todos os que têm a missão de contribuir com uma postura interdisciplinar, com uma formação profissional aliada às demandas do mercado, com a fundamentação teórico-metodológica e com o projeto ético-político da profissão.

Sem a pretensão de aprisionar a formação profissional ao espaço institucional universitário, já que se percebe a graduação como o momento inicial, finito desse processo, e a formação profissional numa perspectiva de totalidade como processo que se dá no infinito, não se pode negar que a universidade constitui o útero que acolhe e desenvolve, nos primeiros momentos de existência os futuros pesquisadores. Daí o destaque das IES em relação à produção do conhecimento; daí a responsabilidade dessas instituições em ter nos seus quadros professores com qualificação para pesquisa, independentemente de serem professores das disciplinas de pesquisa; em ter a obrigação de garantir nos cursos de Serviço Social as orientações das Diretrizes Curriculares, cuidadosamente trabalhadas pelas unidades de ensino sob a maestria da ABEPSS.

Ao se asseverar que todos os professores tenham capacidade para desenvolver pesquisa, e que assumam esse processo como parte do seu fazer profissional como docente, não se tem a pretensão, pelo contrário se considera abominável, de defender a postura de que todos os docentes, por terem a titulação de mestre e de doutor, estejam aptos a assumirem as disciplinas de pesquisa. Estas têm especificidades que vão além da mera transmissão dos conhecimentos da metodologia da pesquisa, pois exigem uma identificação profunda com a produção do conhecimento, um apaixonamento com a prática, a vivência, a maturidade intelectual, o conhecimento do curso e das discussões presentes no Serviço Social e na sociedade.

Pelos motivos citados (e há outros que não cabem no espaço deste ensaio) é que se defende a depuração, assim como é feito para as demais disciplinas constituintes da grade curricular dos cursos de Serviço Social, de profissionais para terem na prática docente a nobre missão de contribuírem de forma mais efetiva e direta com a formação do assistente social pesquisador. Não adianta aos cursos de Serviço Social terem um currículo com muitas disciplinas de pesquisa se não lhes for atribuído o valor que realmente a produção do conhecimento deve ter na formação e na vida profissional; se nelas forem desenvolvidos conteúdos programáticos desarticulados do conteúdo das demais disciplinas curriculares, em que não é oportunizado ao aluno problematizar as facetas pelas quais se manifesta a questão social.

Não adianta, ainda, haver várias disciplinas de pesquisa se a preocupação com o questionamento da realidade, com o conhecimento ontológico e a construção epistemológica verifica-se apenas nelas mesmas, não representando preocupação dos demais docentes no seu objetivar-se em sala de aula.

É indubitável que o Serviço Social vive um novo tempo. Tempos novos, novos tempos que gravaram na memória dos seus protagonistas as marcas da incerteza, do medo em relação ao confronto com as estruturas opressoras; do medo do novo, do desconhecido, do não vivido.

Tempo de recolhimento intelectual

Tempo de inventar/descobrir habilidades

Tempo de despertar interesses até então latentes

Tempo passado, tempo presente; tempo futuro

Tempo finito, tempo infinito ..., o tempo

Tempo da busca, da procura do conhecer

Tempo de prescrutar a realidade

Tempo de construir, desconstruíndo o todo de forma organizada

Tempo de não escamotear as contradições e enfatizar as convergências 
Tempo que é o tempo do Serviço Social no seu historicizar-se

Tempo em que constrói o seu ser e vir a ser quisa

Tempo do enfrentamento aos desafios da pes-

Tempo de repensar a formação e prática profissional.

\section{Referências}

BRASIL. Lei n. 1.889, de 13 de junho de 1953. Dispõe sobre os objetivos do ensino do Serviço Social, sua estruturação e ainda as prerrogativas dos portadores de diplomas de Assistentes Sociais e Agentes Sociais. Lex: coletânea de Legislação e Jurisprudência. São Paulo: v. 8, 1996. (Legislação Federal e Marginalia).

Conselho Federal de Educação. Do parecer no tocante aos aspectos fundamentais a formação profissional do assistente social. Parecer n. 286, aprovado em 10 de outubro de 1962. Relator: José Barreto Filho. Documenta, p. 105-107, Brasília, 1962.

. Conselho Federal de Educação. Do texto apresentando nova redação ao parecer aprovando as modificações apresentadas pela ABESS, no que se refere ao desdobramento da disciplina 'Metodologia do Serviço Social'. Parecer n. 242 aprovado em 13 de março de 1970. Relator: Relator Newton Sucupira. Documenta, p. 221-223, Brasília:. 1970.

. Resolução CNE/CES 6, de 23 de setembro de 1982. Fixa os mínimos de conteúdo e de duração do Curso de Serviço Social, com base no Parecer n. 412/82, homologado pela Ministra da Educação. Brasília, 1982.

. Resolução CNE/CES 15, de 13 de Março de 2002. Estabelece as Diretrizes Curriculares para o Curso de Serviço Social. Diário Oficial da União. Brasília, 9 abr. 2002, Seção 1, p. 33 .

KOSIK, K. Dialética do concreto. Rio de Janeiro: Paz e Terra, 1976.

LEFEBVRE, H. Sociologia de Marx. Rio de Janeiro: Forense Universitária, 1979.

LUKÁCS, G. Ontologia do ser social: os princípios ontológicos fundamentais de Marx. São Paulo: Ciências Humanas, 1979.

MARKUS, G. Teoria do conhecimento no jovem Marx. Rio de Janeiro: Paz e Terra, 1974.

MARTINELLI, M. L. Serviço Social: identidade e alienação. São Paulo: Cortez, 1990.
MARX, K.; ENGELS, F. A ideologia alemã. São Paulo: Grijalbo, 1977.

MARX, K. O Capital: crítica da economia política. Tradução de Reginaldo Sant'Anna. Rio de Janeiro: Civilização Brasileira, 1980. liv. III, v.6, cap. 48.

SETUBAL, A. A. Pesquisa em Serviço Social: utopia e realidade. São Paulo: Cortez, 1995.

VÁZQUEZ, A. S. Filosofia da práxis. Rio de Janeiro: Civilização Brasileira, 1968.

\section{Notas}

1 Aqui,lembra-se deMarxeEngels(1977, p 14)quandocriticaram o materialismo intuitivo de Fuerbach dizendo em sua XI tese que os filósofos se limitaram a 'interpretar' o mundo de diferentes maneiras; oque importaé 'transformá-lo'. Seráque se pode dizer o mesmo em relação ao assistente social?

2 Vázquez(1968,p. 185-186), aodefinirpráxis, fala daimportância de se distinguir atos de atividade, de se estudar a categoria atividade, uma vez que eles não se constituem em sinônimos. Segundo o autor, para que o ato se transforme em atividade faz-se necessário que, desde a sua estruturação, ele esteja articulado como elemento de um todo, "[...] ou de um processo total que culmina na modificação de uma matéria prima".

3 Termo utilizado por Kosik (1973, p. 19) para designar os produtos do homem como elementos autônomos e reduzir o homem "[...] ao nível da práxis utilitária".

4 Apesar de a práxis na filosofia materialista estar presente e se articular em todas as manifestações do homem, e que nessa articulação ela determina a sua totalidade, não se pode confundi-la com trabalho. Isso porque na dialética histórica embora toda práxis seja trabalho, nem todo trabalho se constitui práxis.

5 Segundo Kosik, em obra já citada neste trabalho, é a consciência que toma como seus os resultados dos estudos filosóficos e elabora uma concepção de mundo e realidade de forma acrítica.

6 A práxis aqui referida, desejada e que se defende para o Serviço Social é a práxis social por ter caráter político que se identifica aos interesses da sociedade. Esse tipo de práxis, segundo Vázquez (1968, p. 201), utiliza-se de estratégias e táticas. Em relação à primeira, a atividade desenvolvida a partir da práxis social desenvolve-se de forma processual e em consonância com as necessidades de determinado momento da história geral. Enquanto isso, a segunda procura dentro do momento histórico "[...] cumprir a linha política [...]" necessária, no momento histórico geral para que seja instalada uma nova sociedade. 
7 Adjetivo referente à ontologia. Ontologia é uma palavra de origem grega usada para representar a parte da filosofia que segundo Aristóteles especula o "ser enquanto ser". O ser é a essência onde se encontra a verdade. É o lugar que dá origem ao pensamento da identidade enquanto singularidade. Neste trabalho o termo é usado para atribuir adjetivação não ao ser em si mesmo, mas ao ser enquanto elemento histórico e que, por isso, se constrói e se reconstrói nas relações histórico-sociais. Para aprofundamento dessa compreensão, ver tambémLukács (1979).

8 Nessa perspectiva, a teoria é resultante dos momentos laborativo (atividade objetiva) e existencial (formação da subjetividade) do homem. Esses momentos guardam estreita intimidade entre si, não sendo possível, por isso, concebêlos desligados. Quando ocorre o desligamento, a teoria se transforma em auxiliar da práxis, subsidia técnicas manipuladoras da realidade e do ser humano, ao mesmo tempo em que fortalece o discurso 'saber é poder'.

9 Sendo a questão social resultado da contradição capital/ trabalho, a sua essência está presa à essência do capitalismo. Por isso, assim como no capitalismo, a sua essência tem permanecido inalterada ao longo dos tempos modificandose apenas as suas expressões.

10 Sabe-se que o Serviço Social na sua essência não mudou. Continua sendo uma profissão de caráter prático. O que aqui se coloca é que ele perdeu a condição de 'eminentemente prático' pela vasta produção de conhecimento pela via da pesquisa. Hoje se tem um Serviço Social, não resta dúvida, mais amadurecido teoricamente e com capacidade para entender a realidade e nela atuar com mais competência e eficiência.

11 Graças a esse esforço é que o Serviço Social hoje é reconhecido pelo Conselho Nacional de Desenvolvimento Científico e Tecnológico (CNPq) como área de conhecimento.

12 A procura de espaços para a socialização do conhecimento vem crescendo no Serviço Social. Basta observar o número de inscritos do I ao X ENPESS, sem se falar nos congressos, fóruns de debates e simpósios promovidos por entidades representativas da categoria.

13 Comunicado do X ENPESS com base nos trabalhos selecionados até 24 de outubro de 2006.

14 Segundo a Coordenação Geral do XENPESS, 270 alunos da graduação se inscreveram para participar desse Encontro. Essa demanda já reflete que a pesquisa aos poucos penetra na graduação sob forma de Iniciação Científica. Acredita-se que é uma decorrência das Diretrizes Curriculares que exigem a inclusão de disciplinas de pesquisa nos currículos das unidades de ensino em Serviço Social, e do incentivo dado ao aluno na forma de bolsa de Iniciação Científica. Segundo dados, obtidos por informação verbal, de pesquisa realizada pela Associação Brasileira de Estudos e Pesquisas em ServiçioSocial(ABEPSS), “[...] naavaliação daimplementação das diretrizes curriculares", em 2006, o número de disciplinas de pesquisa constatado nos cursos de Serviço Social do Brasil é em média de seis disciplinas. Em nenhum curso foi identificada a existência de apenas uma disciplina.

\section{Aglair Alencar Setubal \\ Assistente Social \\ Doutora em Serviço Social (PUCSP) \\ Coordenadora do Curso de Serviço Social do Institu- to Camillo Filho}

Av. Dom Severino, 2226 - Jóquei Clube

Teresina - Piauí

CEP: 64051-200 